Proc. Indian Acad. Sci. (Chem. Sci.), Vol. 99, No. 3, September 1987, pp. 137-141. (C) Printed in India.

\title{
Synthesis and spectroscopic investigations of complexes of lanthanide nitrates with 5-nitroisoquinoline-2-oxide
}

\author{
N RAJASEKAR \\ Department of Inorganic and Physical Chemistry, Indian Institute of Science, Bangalore \\ 560012 , India \\ MS received 9 January 1987

\begin{abstract}
New complexes of lanthanide nitrates with 5-nitroisoquinoline-2-oxide (NI$\mathrm{QNO}$ ) of the type $\mathrm{Ln}(\mathrm{NIQNO})_{3}\left(\mathrm{NO}_{3}\right)_{3}$ where $\mathrm{Ln}=\mathrm{La}-\mathrm{Yb}$ and $\mathrm{Y}$ have been synthesised and characterised by analyses, conductance, infrared, proton NMR and electronic spectra. The molar conductance and IR data point to the coordinated nature of the nitrate groups in all the complexes studied. IR spectral analysis along with the proton NMR spectra of the ligand and its (diamagnetic) $\mathrm{La}^{3+}$ and $\mathrm{Y}^{3+}$ complexes unequivocally proves that the coordination of the ligand to the tripositive lanthanide ions taken place through the oxygen of the $\mathrm{N}-\mathrm{O}$ group. From a comparison of the visible electronic spectral shapes of the $\mathrm{Nd}^{3+}$ and $\mathrm{Ho}^{3+}$ complexes, a probable coordination number of eight can be assigned to all the complexes.
\end{abstract}

Keywords. Lanthanide nitrate complexes; 5-nitroisoquinoline-2-oxide; infrared; proton NMR; electronic spectra.

\section{Introduction}

Investigations on the lanthanide complexes of substituted pyridine-1-oxides with substituents other than the methyl group, have led to the conclusion that substituents at the 4-position of the heterocyclic ring are capable of introducing a steric hindrance to coordination and consequently affect the ligand to metal ratio as compared to that in the substituted pyridine-1-oxide complexes (Navaneetham and Soundararajan 1981). To understand the effect of the substituents on the coordination number around the metal ion due to the differences in their nature such as their position in the ring, the bulkiness, electron-donating or -withdrawing tendency, new complexes of lanthanide nitrates with 5-nitroisoquinoline-2-oxide have been synthesised and studied by analyses, conductance, IR, proton NMR and electronic spectra.

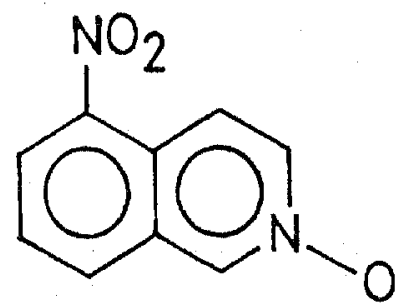




\section{Experimental}

\subsection{Materials}

Isoquinoline was obtained from Fluka Chemicals, Germany. Lanthanide oxides ( $99.99 \%$ pure) were obtained from the American Potash and Chemicals, USA. All the solvents were purified by standard methods.

5-nitroisoquinoline was prepared by nitration of isoquinoline-2-oxide as described by (Katritzky et al 1957) for 4-nitropyridine-1-oxide and recrystallized from chloroform solution (m.p. $219-220^{\circ} \mathrm{C}$; Lit., Ochiai and Ishikawa $1945,220-222^{\circ} \mathrm{C}$ ). Hydrated lanthanide nitrates were prepared as reported earlier (Rajasekar and Soundararajan 1979).

\subsection{Preparation of the complexes}

A solution of lanthanide nitrate ( 1 mmole) in hot ethyl acetate $(15 \mathrm{ml})$ was added slowly with stirring to a boiling solution NIQNO (15 mmoles) in ethyl acetate $(200 \mathrm{ml})$. The stirring was continued for 5 minutes. The precipitated complex was filtered through a sintered crucible $\left(G_{3}\right)$, washed with hot chloroform followed by diethyl ether and finally dried over phosphorus(V) oxide in a vacuum desiccator.

\subsection{Analytical and physical methods}

The metal and anion content of the complexes were estimated by EDTA titrations using xylenol-orange as indicator (Lyle and Rahman 1963). The anion was estimated by gravimetric precipitation with nitron as described by (Welcher 1947). The ligand was estimated spectrophotometrically at $204 \mathrm{~nm}$ using the calibration curve method (Willard et al 1965). The analytical data are presented in table 1 . The IR spectra of the ligand and its lanthanide complexes in nujol (in the region $400-4000 \mathrm{~cm}^{-1}$ ) were recorded on a Perkin-Elmer model 397 spectrophotometer. The important IR bands and their assignments are given in table 2. Proton NMR spectra of the ligand and its diamagnetic $\mathrm{La}^{3+}$ and $\mathrm{Y}^{3+}$ complexes were recorded on a Bruker WH-270 spectrometer operating in the FT mode, using $\mathrm{CD}_{3} \mathrm{CN}$ as solvent and TMS as the internal reference (table 3). Electronic spectra of $\mathrm{Nd}^{3+}$ and $\mathrm{Ho}^{3+}$ complexes in acetonitrile were recorded in the visible region on a Hitachi uv-3400 model spectrophotometer. The solid state spectra for the same complexes

Table 1. Analytical and conductivity data for the complexes of the general formula $\operatorname{Ln}(\mathrm{NIQNO})_{3}\left(\mathrm{NO}_{3}\right)_{3}$

\begin{tabular}{|c|c|c|c|c|c|c|c|}
\hline \multirow[b]{2}{*}{$\mathrm{Ln}^{3+}$} & \multicolumn{2}{|c|}{$\%$ Metal } & \multicolumn{2}{|c|}{$\%$ Ligand } & \multicolumn{2}{|c|}{$\%$ Anion } & \multirow{2}{*}{$\begin{array}{c}{ }^{*} \text { Molar } \\
\text { conductance } \\
\text { in } \mathrm{CH}_{3} \mathrm{CN}\end{array}$} \\
\hline & Found & Calc. & Found & Calc. & Found & Calc. & \\
\hline $\mathrm{La}$ & $15 \cdot 48$ & $15 \cdot 52$ & $63 \cdot 84$ & 63.69 & $20 \cdot 70$ & $20 \cdot 78$ & 14 \\
\hline Nd & $16 \cdot 14$ & 16.02 & $63 \cdot 53$ & $63 \cdot 32$ & $20 \cdot 84$ & $20 \cdot 66$ & 13 \\
\hline Ho & $17 \cdot 84$ & $17 \cdot 91$ & $61 \cdot 64$ & $61 \cdot 89$ & $20 \cdot 40$ & $20 \cdot 20$ & 24 \\
\hline $\mathrm{Er}$ & $18 \cdot 19$ & $18 \cdot 12$ & 61.90 & $61 \cdot 74$ & 20.04 & $20 \cdot 15$ & 17 \\
\hline $\mathrm{Yb}$ & $18 \cdot 56$ & $18 \cdot 63$ & $61 \cdot 41$ & $61 \cdot 35$ & $20 \cdot 22$ & $20 \cdot 02$ & 18 \\
\hline $\mathrm{Y}$ & $9 \cdot 28$ & $9 \cdot 41$ & - & - & - & - & 20 \\
\hline
\end{tabular}

*Values in $\mathrm{Ohm}^{-1} \mathrm{~cm}^{2} \mathrm{~mol}^{-1}$, at $25^{\circ} \mathrm{C}$ 
Table 2. Important infrared frequencies (in $\mathrm{cm}^{1}$ ) and their assignments for NIQNO and its nitrate complexes.

\begin{tabular}{clllllll}
\hline NIQNO & La & Nd & Ho & Er & Yb & Y Assignment \\
\hline- & $1790 v w$ & $1785 v w$ & $1790 w$ & $1785 w$ & $1785 w$ & $1785 w$ & $\left(\nu_{2}+\nu_{3}\right)$ \\
- & $1760 v w$ & $1760 v w$ & $1765 v s$ & $1765 v s$ & $1765 v s$ & $1768 s$ & nitrate \\
- & $1728 w$ & $1728 v w$ & $1728 v s$ & $1728 v s$ & $1730 v s$ & $1730 s$ & $\left(\nu_{2}+\nu_{5}\right)$ nitrate \\
$1522 v s$ & $1528 v s$ & $1528 v s$ & $1528 v s$ & $1525 v s$ & $1522 v s$ & $1525 s$ & $\nu_{4}$ nitrate +ligand \\
$1340 s$ & $1332 v s$ & $1335 v s$ & $1338 v$ & $1335 v s$ & $1335 s$ & $1330 v s$ & $\nu_{\text {NO deformation }}$ d \\
- & $1310 s$ & $1305 s$ & $1325 v s$ & $1305 s$ & $1305 v s$ & $1295 s$ & $\nu_{1}$ nitrate \\
- & $1030 v s$ & $1030 v s$ & $1030 v s$ & $1025 v s$ & $1028 v s$ & $1028 s$ & $\nu_{2}$ nitrate \\
$840 m$ & $845 w$ & $850 v w$ & $845 m$ & $845 m$ & $845 m$ & $845 m$ & $\delta_{\text {NO }}$ \\
$739 m$ & $740 m$ & $742 m$ & $745 v s$ & $742 v s$ & $745 v s$ & $745 v s$ & $\gamma_{\mathrm{CH}}$ \\
\hline
\end{tabular}

Table 3. Proton NMR data for NIQNO and its $\mathrm{La}^{3+}$ and $\mathrm{Y}^{3+}$ complexes in $\mathrm{CD}_{3} \mathrm{CN}$.

\begin{tabular}{lcccccc}
\hline & \multicolumn{6}{c}{ Chemical shifts with respect to TMS $(\delta)$} \\
\cline { 2 - 8 } Compound & $1 \mathrm{H}$ & $3 \mathrm{H}$ & $4 \mathrm{H}$ & $6 \mathrm{H}$ & $7 \mathrm{H}$ & $8 \mathrm{H}$ \\
\hline NIQNO & 8.84 & 8.48 & 7.94 & 8.38 & 7.71 & 8.17 \\
$\mathrm{La}^{3+}$ & 9.68 & 8.54 & 8.11 & 8.42 & 7.84 & 8.26 \\
$\mathrm{Y}^{3+}$ & 9.68 & 8.65 & 8.15 & 8.56 & 7.89 & 8.34 \\
\hline
\end{tabular}

in nujol were recorded in the same region were run on a Cary-14 instrument. Electrolytic conductance measurements in acetonitrile solutions of the complexes were carried out with a Siemens conductivity bridge using an immersion cell (type LTA), previously calibrated with standard $\mathrm{KCl}$ solution. The concentration of the solutions used were of the order of $10^{-3} \mathrm{M}$.

\section{Results and discussion}

Analytical data for the newly prepared complexes listed in table 1 indicate that three molecules of the ligand are associated with each metal ion. All the complexes are soluble in DMSO, DMF and acetonitrile $\left(\mathrm{Ho}^{3+}, \mathrm{Er}^{3+}\right.$ and $\mathrm{Yb}^{3+}$ complexes are slightly insoluble) and insoluble in chloroform, benzene and carbon tetrachloride. Molar conductance values suggest that all the three nitrate groups are non-ionic in nature (Geary 1971).

The absence of the two IR active bands of the nitrate ion $D_{3 h}$ symmetry in all the complexes at 720 and $1390 \mathrm{~cm}^{-1}$ provides confirmatory evidence to the conductance measurements that all the nitrate groups are non-ionic in nature. Nitrate groups are capable of bonding to a metal ion in monodentate or bidentate fashion, in either case the symmetry is lowered from $D_{3 h}$ to $C_{2}$. . The two situations cannot, in general, be unambiguously distinguished on the basis of the IR data alone. The combination bands of the nitrate group which generally appear in the 1700-1800 region have been used for structural assignments of the nitrate groups (Curtis and Curtis 1965; Lever et al 1971). In the present complexes, the presence of three weak 
bands in the said region and the separation between them suggest that both mono and bidentate nitrate groups are present in the complexes studied.

The band at $1340 \mathrm{~cm}^{-1}$ assigned to $\mathrm{N}-\mathrm{O}$ stretching frequency of the ligand shifts to lower frequencies (ca. $5-8 \mathrm{~cm}^{-1}$ ) in the spectra of the complexes indicating the binding of the N-oxide oxygen to the tripositive lanthanide ion. The $\nu \mathrm{N}-\mathrm{O}$ and C-H out-of-plane vibrations at $840 \mathrm{~cm}^{-1}$ and $739 \mathrm{~cm}^{-1}$ of the ligand shift to higher frequencies revealing the coordination of the $\mathrm{N}-\mathrm{O}$ group to the metal ion in the NIQNO complexes of lanthanide nitrates.

Additional evidence for the participation of the oxygen of the $\mathrm{N}-\mathrm{O}$ moiety in coordination with the lanthanide ion is found in the proton NMR spectra of the ligand and its diamagnetic complexes ( $\mathrm{La}^{3+}$ and $\mathrm{Y}^{3+}$ ) (table 3 ). The assignments have been made relative to the reported assignments for 5-nitroisoquinoline (Aramarego and Batterharn 1966).

All proton signals in the $\mathrm{La}^{3+}$ and $\mathrm{Y}^{3+}$ complexes show downfield shifts, confirming the coordination of the $\mathrm{N}$-oxide moiety to the lanthanide ion. The observed deshielding is a consequence of the drainage of electron density towards the lanthanide ion in the complexes. The downfield shifts observed in the $\mathrm{Y}^{3+}$ complexes are greater than those in $\mathrm{La}^{3+}$ complexes, showing the stronger coordination of the ligand through the oxygen of the $\mathrm{N}$-oxide moiety to the metal ion. The variation in the magnitude of deshielding of the heterocyclic ring protons in the lanthanide nitrate complexes $\left(\mathrm{La}^{3+}\right.$ and $\mathrm{Y}^{3+}$ ) of NIQNO (in comparison with IQNO complexes, Rajasekar 1986), is a consequence of the influence of the substituents at the 5-position of the isoquinoline-2-oxide ring on the strength of the metal-ligand bond.

Electronic spectral data are given in table 4 . The sharp $f-f$ bands exhibit red shifts with respect to the aquo ions consequent on complex formation. The red shift called the nephelauxetic shift, is a measure of the covalency in the metal-ligand bond. Sinha $(1966,1971)$ has proposed a $\delta$ scale to express the covalent character of the metal-ligand bond, which is given by the relation,

$$
\delta(\%)=[(1-\beta) / \beta] \times 100,
$$

where $\beta$ is the average value of the ratio $\nu$ complex/ $\nu$ aquo. The $\delta$ values calculated for $\mathrm{Nd}^{3+}$ and $\mathrm{Ho}^{3+}$ complexes of NIQNO are presented in table 4. The shapes of the hypersensitive bands of the $\mathrm{Nd}^{3+}$ and $\mathrm{Ho}^{3+}$ complexes resemble

Table 4. Electronic spectral data and their assignments (in DMSO).

\begin{tabular}{|c|c|c|c|}
\hline \multicolumn{2}{|c|}{$\mathrm{Nd}^{3+}$} & \multicolumn{2}{|c|}{$\mathrm{Ho}^{3+}$} \\
\hline$J$ level & Energy (KK) & $J$ level & Energy (KK) \\
\hline $4_{G_{9 / 2}}$ & $19 \cdot 53$ & $5_{F_{3}}$ & $20 \cdot 52$ \\
\hline $4_{G_{7 / 2}}$ & $19 \cdot 02$ & $5_{F_{4}}, 5_{F_{S 2}}$ & $18 \cdot 47$ \\
\hline $2_{G_{7 / 2}}$ & $17 \cdot 13$ & $5_{F_{5}}$ & $15 \cdot 35$ \\
\hline & $\delta=0.9897$ & & $\delta=1.07$ \\
\hline
\end{tabular}


markedly the shapes of the eight-coordinate lanthanide perchlorate complexes of N-(2-pyrimidyl)benzamide (Rajasekar 1980).

The position, shape and relative intensities were found to be identical both in the solid state spectra recorded in Nujol and in the solution spectra taken in acetonitrile. In short, the same eight-coordinate geometry is observed in both the states and, hence, the compatibility in the solid state properties, such as infrared and solution properties as well as conductivity and NMR.

On the basis of the available evidence, a tentative coordination number of eight can be suggested for all the complexes of NIQNO.

\section{Acknowledgements}

The author is thankful to CSIR, New Delhi, for a Pool Officer position, the authorities of the Indian Institute of Science, Bangalore, for facilities and the Sophisticated Instrument Facility for the NMR spectra.

\section{References}

Aramarego W L F and Batterharn T J 1966 J. Chem. Soc. B 750

Curtis N F and Curtis Y M 1965 Inorg. Chem. 4804

Geary W J 1971 Coord. Chem. Rev. 781

Katritzky A R, Randall E W and Sutton L E 1957 J. Chem. Soc. $176 \mathrm{~g}$

Lever A B P, Mantovani E and Ramaswamy B S 1971 Can. J. Chem. 491957

Lyle S S and Rahman M M 1963 Talanta 101177

Navaneetham N S and Soundararajan S 1981 Proc. Indian Acad. Sci. (Chem. Sci.) 90439

Ochiai E and Ishikawa M 1945 J. Pharm. Soc. Jpn. A 654, (1951) Chem. Abstr. 458527

Rajasekar N and Soundararajan S 1979 Bull. Soc. Chim. Belg. 88773

Rajasekar N 1980 Studies in lanthanide chemistry, Ph.D. thesis, Indian Institute of Science, Bangalore

Rajasekar N 1986 Syn. React. Inorg. Met.-Org. Chem. 161109

Sinha S P 1966 Spectrochim. Acta 2257

Sinha S P $1971 \mathrm{~J}$. lnorg. Nucl. Chem. 332205

Welcher F J 1947 Organic analytical reagents (New York: Von Nostrand)

Willard H H, Merrit L L and Dean J A 1965 Instrumental methods of analysis 4th edn (New Dethi: Affiliated East West) p. 89 